\title{
INORGANIC -ORGANIC NANOCOMPOSITE \\ MATERIALS BASED ON MACROCYCLIC COMPOUNDS
}

\author{
E.Ruiz-Hitzky", B.Casal, P.Aranda and J.C.Galván \\ Instituto de Ciencia de Materiales de Madrid, CSIC, Cantoblanco, \\ 28049-Madrid, Spain
}

\section{LIST OF CONTENTS}

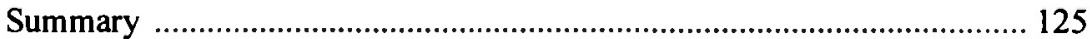

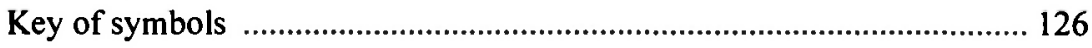

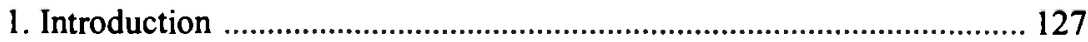

2. Intercalation of crown-ethers and cryptands in layered silicates ............ 128

2.1. Intercalation mechanism ............................................................ 131

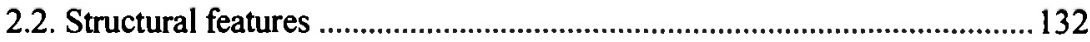

2.3. Properties and applications …………........................................ 136

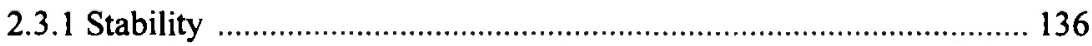

2.3.2. Membranes based on crown-ether intercalation materials ............. 137

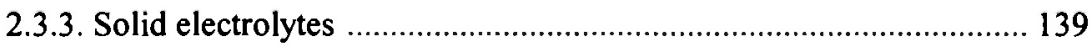

3. Macrocycle intercalations in other 2D solids .................................... 142

4. Entrapping of macrocycles by sol-gel ............................................... 145

5. Grafting of macrocycles on silica surfaces ......................................... 149

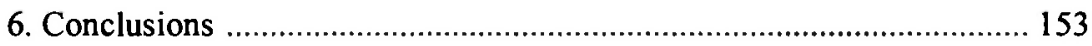

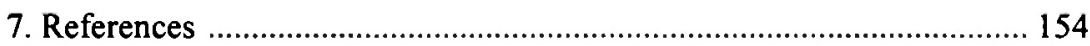

\section{SUMMARY}

The synthesis, structural characterisation, properties and applications of inorganic-organic hybrid materials (nanocomposites) containing macrocycles are reviewed. Three different ways to prepare such materials are discussed: i)

*Author for correspondence:

FAX: +34-91-3720623 e-mail: eduardo@icmm.csic.es 
intercalation in layered host solids, ii) entrapping into inorganic matrices generated by sol-gel, and iii) grafting of macrocycles on inorganic surfaces. Macrocyclic compounds, as crown ethers and cryptands, were the guest organic species used in intercalation processes. The host inorganic solids were layered silicates, vanadium pentoxide xerogel, transition-metal dichalcogenides and phosphorus trichalcogenides. The resulting nanocomposites present synergic host-guest properties useful for applications as solid electrolytes, ion-selective membranes and electrochemical sensors. Alternatively, nanocomposites based on macrocycles can be obtained by entrapping of such compounds into inorganic matrices generated by sol-gel, using different organosilanes as precursors (TMOS, TEOS, ETEOS, MAPTMS, etc). Electrodes based on such systems are sensitive to alkaline cations, lead, silver and ammonium ions giving linear potentiometric responses in a wide concentration range. Finally, the grafting of macrocycles on inorganic surfaces is also discussed. Silica can be functionalised by anchorage of macrocycles able to confer specific properties and reactivity to the inorganic substrate. The main applications of this last class of nanocomposites have been found for chromatography purposes, including separation of cations, anions and non-electrolytic organic compounds.

Key of symbols

$\begin{array}{ll}\text { 12C4 } & \text { 12-crown-4 } \\ \text { 15C5 } & \text { 15-crown-5 } \\ \text { 18C6 } & \text { 18-crown-6 } \\ \text { 2D } & \text { bi-dimensionally arranged solids (layered solids) } \\ \text { AZA18C6 } & \text { azacrown-18C6 (1,10-diaza-18-crown-6) } \\ \text { B15C5 } & \text { mono-benzo-15-crown-5 } \\ \text { B18C6 } & \text { mono-benzo-18-crown-6 } \\ \text { B21C7 } & \text { mono-benzo-21-crown-7 } \\ \text { C(221) } & \text { cryptand (2,2,1) } \\ \text { C(222) } & \text { cryptand (2,2,2) } \\ \text { CHEMFETs } & \text { chemically modified field effect transistors } \\ \text { DB18C6 } & \text { di-benzo-18-crown-6 } \\ \text { DB24C8 } & \text { di-benzo-24-crown-8 } \\ \text { DTA } & \text { differential thermal analysis } \\ \text { DTG } & \text { differential thermal gravimetry }\end{array}$




$\begin{array}{ll}\text { ETEOS } & \text { ethyltriethoxysilane } \\ \text { FTIR } & \text { Fourier transform infrared spectroscopy } \\ \text { IR } & \text { infrared spectroscopy } \\ \text { ISFETs } & \text { ion-sensitive field-effect transistors } \\ \text { ITO } & \text { indium-tin oxide } \\ \text { LDH } & \text { layered double hydroxyde } \\ \text { LMMS } & \text { laser microprobe mass analysis } \\ \text { MAO } & \text { 6-oxa-3,9-dithiabicycle [9,3,1] pentadeca-1(15)-11-13-triene } \\ \text { MAPTMS } & \gamma \text {-methacryloxypropyltrimethoxysilane } \\ n \text {-BuLi } & \text { n-butyllithium } \\ \text { NMR } & \text { nuclear magnetic resonance } \\ \text { PAN } & \text { polyacrylonitrile } \\ \text { PEO } & \text { poly(ethylene oxide) } \\ \text { PTC } & \text { phase transfer catalysis } \\ \text { PVC } & \text { poly(vinyl chloride) } \\ \text { SEM } & \text { scanning electron microscopy } \\ \text { TEOS } & \text { tetraethylorthosilicate } \\ \text { TGA } & \text { thermo-gravimetric analysis } \\ \text { TMOS } & \text { tetramethoxyortosilicate } \\ \text { XRD } & \text { X-ray diffraction }\end{array}$

\section{INTRODUCTION}

Nowadays, composite inorganic-organic hybrid materials, combined at molecular level, are receiving considerable research interest $/ 1 /$. This class of materials are currently known as nanocomposites, in relation with the interactions between the inorganic and organic moieties that take place at the nanometer scale $/ \mathrm{lb} /$. Complementary or synergetic effects between both parts, inorganic and organic, could be of crucial importance to determine the properties of these systems, improving in some cases the behaviour of each of them separately. The so-called crystalline/molecular engineering could be used to design, prepare, characterise and study the properties of such materials with a view to their applications, until the searched predetermined behaviour is optimised. In this way solids of interest in advanced technologies and potential applications such as membranes and electrodes for electrochemical devices, mixed ionic-electronic conductors, optical and optoelectronic materials and heterogeneous catalysts have been prepared. 
The aim of this work is to review the synthesis, the structural organisation and the properties of inorganic-organic nanocomposite materials based on silicates and silica derivatives containing oxyethylene macrocyclic compounds, mainly crown-ethers. Preparation of materials with macrocycles as crown-ethers and cryptands homogenously distributed into inorganic solid matrices could be achieved following three different ways that will be discussed in this paper: i) intercalation in layered host solids, ii) entrapping into inorganic matrices generated by sol-gel, and iii) grafting of macrocycles on inorganic surfaces.

The present contribution mainly deals with results derived from our own experience, i.e. on nanocomposites prepared by intercalation of crown-ethers and cryptands in 2:1 charged silicates and also in other 2D host lattices, as vanadium pentoxide xerogel or certain transition metal disulphides. Results on the inclusion of macrocycles into organopolysiloxane matrices will also be considered here, together with some illustrative examples of immobilisation of crown-ethers on silica surfaces, following grafting reactions reported by different authors.

As we will discuss in this review, the peculiar properties of nanocomposites, resulting from the incorporation of different macrocyclic ligands into inorganic matrices, lead to controlled ion-mobility behaviour useful for applications as solid electrolytes and ion-selective membranes of interest for applications as electrochemical sensors.

\section{INTERCALATION OF CROWN-ETHERS AND CRYPTANDS IN LAYERED SILICATES}

Intercalation of different types of macrocyclic compounds into layered (2D) host solids, giving nanocomposites with synergic host-guest properties, is a topic deeply studied during the last two decades. Some representative examples are collected in Table 1.

The intercalation of crown-ethers, aza-crowns and cryptands into an inorganic solid was first reported by Ruiz-Hitzky and Casal for 2:1 layer silicates $/ 2 /$ containing exchangeable cations in their interlayer space. The process follows a topotactic, way involving the replacement of the solvation shell of the interlayer cations by the macrocyclic compounds as schematised in Fig 1. 


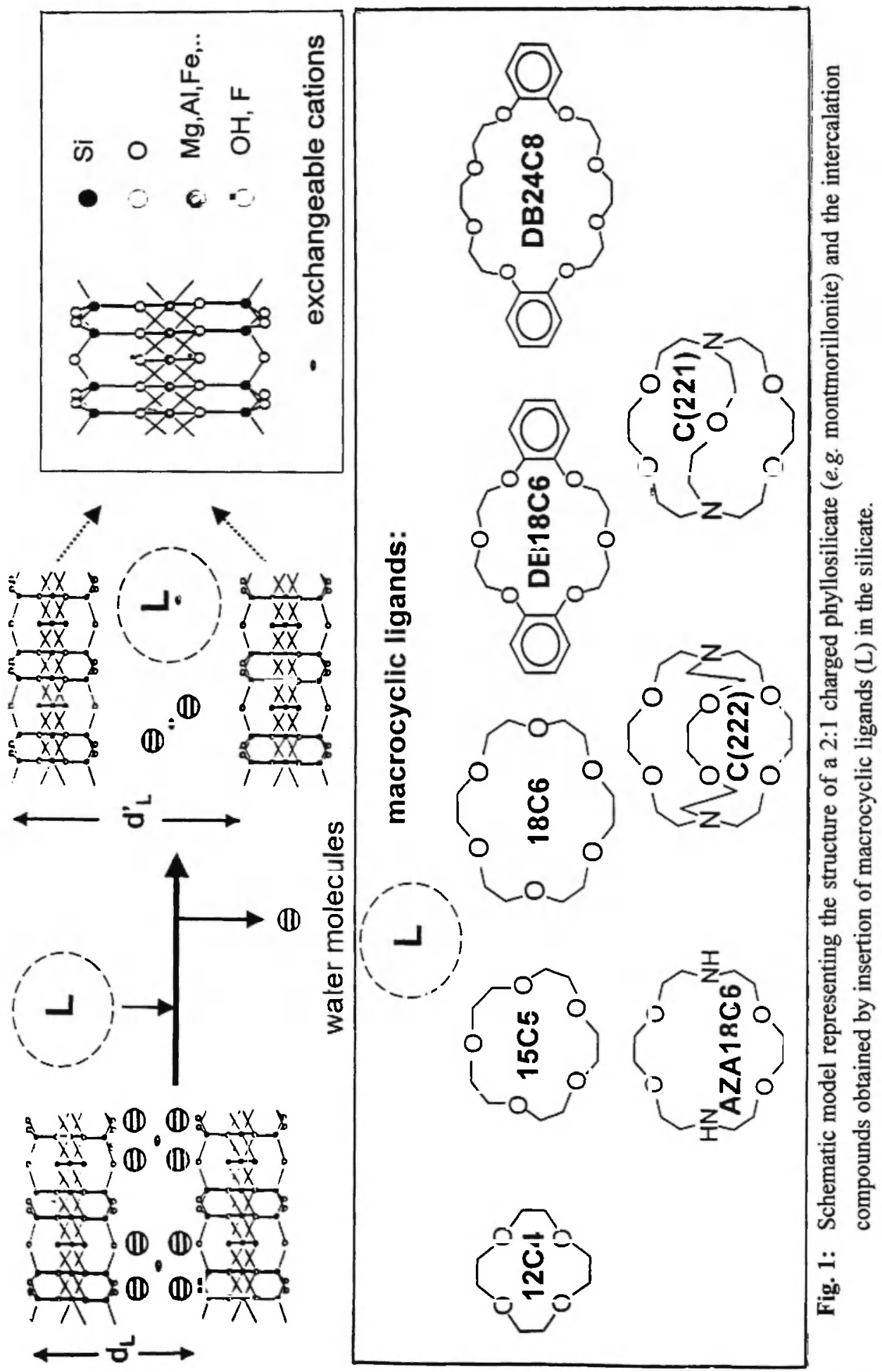


Vol. 21, Nos. 1-2, 2001 Nanocomposite Materials Based on Macrocyclic Compounds

Table 1

Examples of nanocomposites prepared by intercalation of macrocycles in inorganic layered solids

\begin{tabular}{|c|c|c|}
\hline Solid hosts & Macrocycles & $\begin{array}{l}\text { Authors } \\
\text { (references) }\end{array}$ \\
\hline $\begin{array}{l}\text { Phyllosilicates } \\
\text { (montmorillonite, } \\
\text { hectorite, vermiculite, } \\
\text { laponite,...) }\end{array}$ & $\begin{array}{l}\text { crown-ethers } \\
\text { azacrowns } \\
\text { cryptands }\end{array}$ & $\begin{array}{l}\text { Ruiz-Hitzky \& Casal /2,5/ } \\
\text { Casal \& Ruiz-Hitzky /6,9/ } \\
\text { Casal et al. } / 7,8,17 / \\
\text { Aranda et al. /11,24,27/ } \\
\text { Guignard \& Pezerat /78/ }\end{array}$ \\
\hline Phyllosilicates & porphyrins & $\begin{array}{l}\text { Kosiur } / 79 / \\
\text { Cady \& Pinnavaia } / 80 / \\
\text { Van Damme et al. } / 81 / \\
\text { Canesson et al. } / 82 / \\
\text { Abdo et al. } / 83 /\end{array}$ \\
\hline $\begin{array}{l}\text { Hydrated vanadium } \\
\text { pentoxide }\end{array}$ & $\begin{array}{l}12 \mathrm{C} 4,15 \mathrm{C} 5 \\
18 \mathrm{C} 6\end{array}$ & $\begin{array}{l}\text { Ruiz-Hitzky et al. } / 35 / \\
\text { Aranda et al. } / 28 /\end{array}$ \\
\hline Graphite oxide & $15 \mathrm{C} 5$ & Guerrero et al. $/ 84 /$ \\
\hline $\begin{array}{l}\text { Layered chalcogeno- } \\
\text { phosphates }\end{array}$ & $15 \mathrm{C} 5, \mathrm{~B} 15 \mathrm{C} 5$ & Glueck et al. /42/ \\
\hline Iron(III) oxychloride & azacrowns & Herber \& Cassell /85/ \\
\hline $\begin{array}{l}\text { Layered chalcogenides } \\
\left(M S_{2} \cdot M=T a, T i\right)\end{array}$ & AZA18C6 & Villanueva \& Ruiz-Hitzky /86/ \\
\hline $\begin{array}{l}\text { Layered chalcogenides } \\
\text { (delaminated } \mathrm{MoS}_{2} \text { ) }\end{array}$ & $\begin{array}{l}12 \mathrm{C} 4,15 \mathrm{C} 5 \\
18 \mathrm{C} 6\end{array}$ & Lara \& Ruiz-Hitzky /40/ \\
\hline
\end{tabular}

Montmorillonite is the natural layer silicate that was mostly used as host lattice for the macrocycles intercalation. Such silicate is a clay mineral belonging to the smectite group, whose structure (Fig. 1) consists of negatively charged layers that are constituted by two tetrahedral silica sheets and a central octahedral sheet of magnesia or alumina $/ 3 /$. The existence of isomorphous substitutions is the origin of the negative charge in the silicate layers which is compensated by cations (exchangeable cations) as extraframework ions located in the interlayer space. Homoionic montmorillonite samples, i.e. silicates where all the exchangeable cations are of the same nature as for instance $\mathrm{Na}^{+}$(i.e. Na-montmorillonite), are easily prepared by 
equilibrating the aqueous dispersions of the silicate with salt solutions of different metals (alkaline, alkaline-earth, transition metal,...). The interlayer cations are accessible to water and other polar molecules, which could be intercalated in the silicate following different mechanisms $/ 4 /$.

\subsection{Intercalation mechanism}

The complexation of the interlayer cations of montmorillonite, and related silicates, by macrocyclic polyethers is a spontaneous process facilitated by the previous replacement of the hydration shell of the interlayer cations by a polar solvent as methanol. The first step consists of the following solvent exchange reaction:

$$
\mathrm{M}^{\mathrm{n}+}\left(\mathrm{H}_{2} \mathrm{O}\right)_{\mathbf{x}}+\mathrm{yCH}_{3} \mathrm{OH} \leftrightarrows \mathrm{M}^{\mathrm{n}+}\left(\mathrm{CH}_{3} \mathrm{OH}\right)_{\mathrm{y}}+\mathrm{xH}_{2} \mathrm{O}
$$

In a second step, the methanol-saturated silicate is treated with the selected macrocyclic (L) solution, as schematised in Fig.l. The characterisation /5-8/ of the resulting intercalation materials revealed the formation of true interlayer macrocycle-cation complexes in the intracrystalline region of the silicate.

The kinetics of the intercalation process, studied in a set of selected macrocycles (crown-ethers and cryptands), fit reasonably well with postulated equations for bidimensional controlled-diffusion processes $/ 9 /$. As is well known, in conventional homogeneous media, the macrocycle-cation complexes formation requires a deep rearrangement of the cation solvation shell $/ 10 /$, the solvent being replaced to a certain extent by the macrocyclic ligand. The whole enthalpy of the process could be positive or negative depending on factors such as the nature of the solvent and the fitting of cation and macrocyclic ligand /10\%. In heterogeneous conditions, i.e. in the intracrystalline environment of a phyllosilicate as montmorillonite, an exothermic signal corresponding to the intercalation reaction has been determined by microcalorimetric measurements 111\%. From both the intercalation heat and the chemical analysis data, the adsorption enthalpy of the whole process (insertion of the macrocycle and desorption of solvent molecules) was determined. Assuming that the energetic balance involved in the overall process is mainly related with complexation and, consequently, with the stability of the intercalated complex, the sequence of stability for macrocycle/Na-montmorillonite interlayer complexes /11/ appears to be quite similar to that found in homogeneous media using the same solvent (i.e. $\mathrm{CH}_{3} \mathrm{OH}$ ) to dissolve the macrocycle:

$$
\mathrm{C}(222) \gg>18 \mathrm{C} 6>15 \mathrm{C} 5>\mathrm{DB} 24 \mathrm{C} 8>12 \mathrm{C} 4
$$




\subsection{Structural features}

In general, the macrocyclic intercalation compounds involving homoionic $\mathrm{M}^{\mathrm{n}+}$-smectites $\left(\mathrm{M}^{\mathrm{n}+}=\mathrm{Li}^{+}, \mathrm{Na}^{+}, \mathrm{Sr}^{2+}, \mathrm{Ba}^{2+}, \mathrm{NH}_{4}{ }^{+}\right.$, etc) exhibit relatively good crystalline organisation along the $\mathbf{c}$ axis of the silicate, as deduced from the $00 l$ rational orders in the XRD patterns. A representative example is illustrated in Fig. 2, where the XRD patterns of two oriented films corresponding to a homoionic smectite (Sr-montmorillonite), intercalated either by a crown-ether (15C5) or by a cryptand (C222), are shown /8/. From these $001 \mathrm{XRD}$ peaks, it is possible to determine, with very good precision, the increase of the distance between consecutive layers of the silicate (namely as basal spacing, $\mathrm{d}_{\mathrm{L}}$ ) due to the penetration of the macrocycles into the intracrystalline region.

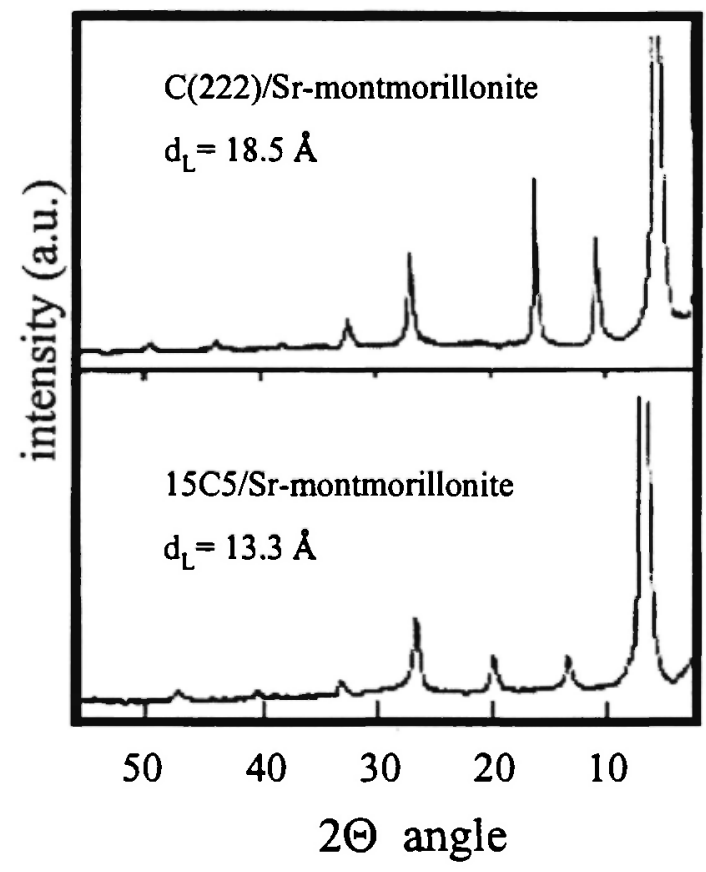

Fig. 2: XRD patterns of Sr-montmorillonite intercalated by $\mathrm{C}(222)$ and $15 \mathrm{C} 5$ respectively, showing the $00 \mathrm{l}$ regular reflections from which $\mathrm{d}_{\mathrm{L}}$ values are calculated /8/. The diagrams were registered from samples as self-supporting films with the particles oriented along the $(\mathbf{a}, \mathbf{b})$ plane of the silicate. 
The structural arrangement of intracrystalline macrocylic complexes formed in the interlayer space of phyllosilicates is comparable to conventional macrocycle-salt complexes formed from solutions. So, the factors influencing its structure are: i) charge and size of the interlayer cations, and ii) cavity radius of the macrocycle $/ 12 /$. Moreover, in the case of the intracrystalline complexes, steric hindrance of the macrocyclic ligands can also influence the arrangement of these complexes. Taking into account the values of the basal spacing increase $\left(\Delta \mathrm{d}_{\mathrm{L}}\right)$ and the amount of macrocycle/cation ratio deduced from the chemical analysis, different structural arrangements of intracrystalline complexes have been postulated $/ 8 \%$. So, a set of representative macrocycle-montmorillonite complexes illustrating its disposition in the interlayer region of the silicate is shown in Fig. 3.

\begin{tabular}{|c|c|c|c|}
\hline $\begin{array}{c}\text { interlayer } \\
\text { arrangement }\end{array}$ & $\begin{array}{l}\mathbf{r}_{\mathbf{c}} / \mathbf{r}_{\mathbf{i}} \\
\text { ratio }\end{array}$ & $\Delta d_{L}(\AA)$ & examples \\
\hline च्यa & $>1$ & $\sim 4$ & $\begin{array}{l}\text { 15C6/Na-mont.; } 18 \mathrm{C} 6 / \mathrm{Ba}-\text { mont } \\
\text { AZA } 18 \mathrm{C} 6 / \mathrm{Li}-\text { mont. }\end{array}$ \\
\hline$\overline{\underline{\mathbb{R}^{2}}}$ & $<1$ & $\sim 4$ & $12 \mathrm{C} 4,15 \mathrm{C} 5,18 \mathrm{C} 6 / \mathrm{K}$ - and $\mathrm{NH}_{4}$-mont. \\
\hline 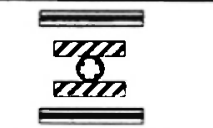 & $<1$ & $\sim 8$ & 12C4/Na-mont. ; 15C5/Ba-mont \\
\hline & $<1$ & $6-7$ & 12C4/Sr-mont. ; 12C4/Ba-mont \\
\hline क्ष & $>1$ & $\sim 6$ & 18C6/Na-mont. \\
\hline & $\begin{array}{l}<1 \\
\text { or } \\
>1\end{array}$ & $6-8$ & $\begin{array}{c}\mathrm{C}(221), \mathrm{C}(222) / \mathrm{M} \text {-mont. }(\mathrm{M}=\mathrm{Li}, \mathrm{Na}, \mathrm{K} \\
\mathrm{Cs}, \mathrm{Ba}, \mathrm{Sr}, \mathrm{Cu}, \mathrm{Ni}, . .)\end{array}$ \\
\hline
\end{tabular}

Fig. 3: Proposed models for interlayer complexes of macrocycles into homoionic montmorillonites according to references $5,8,14,27$. 
Values of $\Delta d_{L}$ are often close to $4 \AA$, which can be interpreted as a coplanar orientation of the ligands relative to the $(a, b)$ plane defined by the silicate layers. This orientation occurs even when the molecular area of the macrocycle exceeds the available area per intracrystalline cation. One-dimensional Fourier-transform $\mathrm{X}$-ray analysis applied to the $15 \mathrm{C} 5 / \mathrm{Na}$-montmorillonite complex shows that the $\mathrm{Na}^{+}$ions are located at $0.75 \AA$ from the plane defined by the five oxygens of the $15 \mathrm{C} 5$ ligand /8/. Similar distance value was found by Bush and Truter in the mono-benzo-15-crown-5/Nal crystalline complex /13/. The exceptional value reported when $18 \mathrm{C} 6$ is intercalated into Na-smectite $\left(\Delta \mathrm{d}_{\mathrm{L}} \approx 6.4 \AA\right)$ has been interpreted $/ 8 /$ as a particular conformation of the interlayer complex as illustrated in Fig. 3. Bulky crown-ethers such as DB18C6 or DB24C8 also give higher increases of the basal spacing, in these cases due to steric hindrance imposed by the aromatic ring.

As occurs in homogenous media, for $r_{c} / r_{i}$ ratio $<1\left(r_{c}=\right.$ intra-macrocycle cavity "radius"; $r_{i}=$ ionic radius of interlayer cations), a marked tendency to form 2:1 ligand/cation coordinations has been observed. The $\Delta \mathrm{d}_{\mathrm{L}}$ values found in these cases ( 8 or 6-7 $\AA$ ) are compatible with a coplanar or tilted orientation of the "sandwich" complexes formed in the intracrystalline space. A remarkable exception to that behaviour occurs for $\mathrm{K}^{+}$and $\mathrm{NH}_{4}{ }^{+}$homoionic smectites, where the chemical analysis and the $\Delta \mathrm{d}_{\mathrm{L}}$ found $(\approx 4 \AA)$ indicates the formation of 1:1 interlayer complexes. The tendency of these cations to be included into the "hexagonal hole" of the silicate /14/ appears to be the cause of the irregular behaviour detected.

Finally, it should be pointed out that the intracrystalline complexes formation is usually complicated due to the competition of interlayer cations to coordinate different oxygen atoms, i.e. those belonging to either the surface silicate sheet, or the macrocyclic compound, or the remaining water molecules.

Intercalation of the aza-crown compound, $\mathrm{AZA18C6}$, in homoionic montmorillonite gives $1: 1$ complexes with $\Delta \mathrm{d}_{\mathrm{L}}$ values of about $4 \AA$, showing also a planar disposition of the macrocyclic ring with respect to the $(\mathbf{a}, \mathbf{b})$ plane of the silicate. Those compounds can also act as ligands for intracrystalline cations of high hydration energy such as transition metal-ions. Nevertheless, in some cases $\left(\mathrm{Ca}^{2+}\right.$ and $\mathrm{Mg}^{2+}$ homoionic montmorillonites), non-regular interstratified materials are obtained $/ 8 /$.

On the other hand, intercalation of polyoxadiaza-macrobicyclic ligands (cryptands) into homoionic 2:1 charged phyllosilicates always produces 1:1 complexes, for samples of the silicates exchanged with low hydration energy cations. In the latter complexes, it appears from the ${ }^{23} \mathrm{Na}$ NMR study that the 
interlayer cations are encapsulated by the ligand. A homogenous oxygen environment has been recognized under the complete absence of interlayer water molecules $/ 8,11 /$. Intercalation of $\mathrm{C}(222)$ and $\mathrm{C}(221)$ into homoionic 2:1 phyllosilicates saturated by transition metal-ions leads to $\Delta d_{L}$ values comprised between 6-8 $\AA$, which are close to the diameter length of the spherical macrobicyclic ligands /15/. Interestingly, the acidity associated with water molecules belonging to the coordination shell of this type of interlayer cations produces the protonation of the $\mathrm{N}$ atoms of the macrocyclic ligand avoiding metal complexation. This behaviour was not only evidenced by IR spectroscopy 16/ but also by laser microprobe mass spectrometry (LMMS) analysis 17/. LMMS is a useful tool for characterisation of fragments, emitted from a solid with the aid of a laser, being analysed in a time-of-flight mass spectrometer. This technique, that was applied for the first time by Casal and co-workers $17 /$ in the analysis of inorganic-organic materials, allowed them to detect in $\mathrm{C}(222)$ intercalated into $\mathrm{M}^{2+}$-montmorillonites $(\mathrm{M}=\mathrm{Cu}, \mathrm{Ni}) \mathrm{m} / \mathrm{e}$ values corresponding to $[\mathrm{C}(222)+1]$ mass units, i.e. $\mathrm{m} / \mathrm{e}=377$ typical of protonated cryptand (Fig. 4). No signal corresponding to the $\mathrm{m} / \mathrm{e}$ values of $[\mathrm{C}(222) / \mathrm{M}]^{\mathrm{n}+}$ complexes was detected, whereas for $\mathrm{C}(222)$ intercalated in $\mathrm{Na}^{+}$homoionic silicates the molecular peak at $\mathrm{m} / \mathrm{e}=399$ mass units was clearly observed, indicating the existence of true $[\mathrm{C}(222) / \mathrm{Na}]^{+}$interlayer complexes $/ 6,7 \%$.

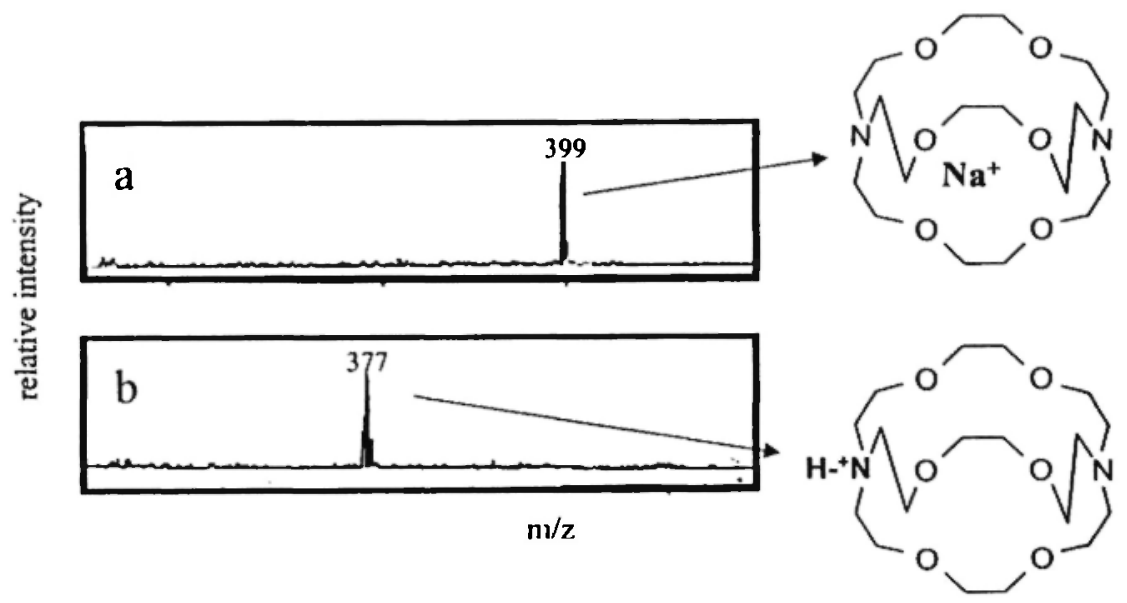

Fig. 4: LMMS mass spectra of $\mathrm{C}(222)$ intercalated into Na-montmorillonite (a) and $\mathrm{Cu}(\mathrm{II})$-montmorillonite (b) respectively, according to the results proposed by Casal et al. $/ 7 /$. 
Coordination of interlayer sodium ions with cryptand ligands was also corroborated by ${ }^{23} \mathrm{Na}-\mathrm{NMR}$ spectroscopy. Thus, the NMR spectrum of $\mathrm{C}(222) / \mathrm{Na}$-hectorite ${ }^{\#}$ compound presents two signals at -10.4 and $-12.9 \mathrm{ppm}$, that could be assigned to both cations coordinated with the oxygens of the cryptand, and to uncomplexed ions interacting with other oxygen atoms (silicate internal surface and/or remaining water molecules). Further vacuum thermal treatment $\left(110^{\circ} \mathrm{C}, 10^{-3} \mathrm{Torr}\right)$ changes the spectrum, showing a single signal at $-15.1 \mathrm{ppm}$ that has been attributed to an uniform environment compatible with the $\mathrm{Na}^{+}$ion inclusion into the macrobicyclic ligand /8/. This assumption is supported by the analogy in the chemical shift values $(-16.2 \mathrm{ppm})$ found in these intercalation compounds and in the crystalline $\mathrm{C}(222) / \mathrm{Nal}$ complex $/ 16 /$.

\subsection{Properties and applications}

\subsubsection{Stability}

The complexes of macrocycles formed in layer silicates show high stability towards organic solvents and salt solution treatments. It has been reported /17/ that the desorption of crown-ethers from the solids could be achieved by treatment with concentrated alkylammonium salt solutions (e.g. propylammonium chloride), as illustrated in Equation 2:

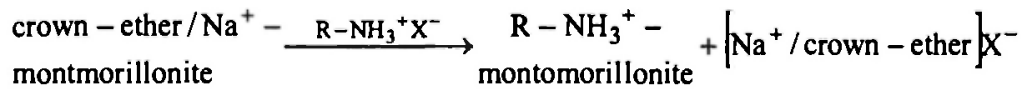

The resulting alkylammonium-silicate could be easily exchanged with $\mathrm{NaCl}$ solutions, the sodium form of the montmorillonite being able again to intercalate crown-ethers. The application of this procedure to complexes formed by intercalation of cryptands leads to protonated macrobicycles that remain inside the montmorillonite host lattice $/ 17 \%$. To obtain the electrical balance of the silicate, it should be supposed that exchangeable cations of the silicate might pass to the solution and also, that the alkylammonium ions acceding to the interlayer space give the corresponding amine, following a proton-transfer process in the reaction with the cryptand.

\footnotetext{
"hectorite is a natural 2:1 charged phyllosilicate, with analogous behaviour than montmorillonite but without appreciable amounts of paramagnetic elements, as iron, and therefore useful for solid state NMR high resolution studies.
} 
The elevated thermal stability of macrocyclic intercalation compounds has been deduced from the TGA, DTG and DTA results $/ 11,17 /$. As a general rule, the weight loss of macrocycles intercalated in homoionic 2:1 phyllosilicates, occurring between 25 and $700^{\circ} \mathrm{C}$, takes place in three consecutive steps: the first one $\left(\mathrm{T}<150^{\circ} \mathrm{C}\right)$ has been related with the loss of water (remaining water molecules at the interlayer space and physically adsorbed upon exposing the samples to the atmosphere humidity). The second step, that appears at $350-450^{\circ} \mathrm{C}$, was attributed to an exothermic process associated with the loss of the organic ligands due to their combustion. In the absence of oxygen (vacuum or nitrogen flux) the loss of ligands occuring in the $250-350^{\circ} \mathrm{C}$ range are observed as endothermic peaks. Some differences in the temperature of such endothermic processes depend on the nature of the macrocyclic compound. The third step, above $550^{\circ} \mathrm{C}$, corresponds to the endothermic process associated with the dehydroxylation of the host lattice $/ 18,19 /$.

The benzo-crowns like DB18C6 intercalated in phyllosilicates give, in the absence of oxygen, thermal modifications up to $350^{\circ} \mathrm{C}$, that were related to intracrystalline polycondensation of benzene rings $/ 11$, in analogy with the polyphenylene species intercalated into montmorillonite reported by Soma and coworkers $/ 20 \%$. Such species are of interest due to their behaviour as electronic conductors.

\subsubsection{Membranes based on crown-ether intercalation materials}

Crown-ethers and cryptands used for preparation of liquid and polymersupported membranes $/ 21,22 /$ have been also immobilized on inorganic solids to prepare ion-selective membranes. In this way, some $2: 1$ phyllosilicates (clay minerals) presenting the ability to give stable colloids, were used for preparation of membranes where theoretically a facilitated transport mechanism could be operative $123 /$. For this purpose membranes, containing montmorillonite intercalated by crown-ethers used as the active phase of the membrane, have been prepared as self-supporting films coated by polybutadiene covering both faces of the inorganic-organic films (i.e. in a sandwich form) $24 \%$. The resulting composite membranes show good mechanical properties, allowing manipulation, as opposed to materials only constituted by the clay intercalated film. The SEM image (Fig. 5) of a membrane containing 18C6/Na-montmorillonite shows the cross-section, where aggregates of the clay-intercalated particles appear well arranged along 


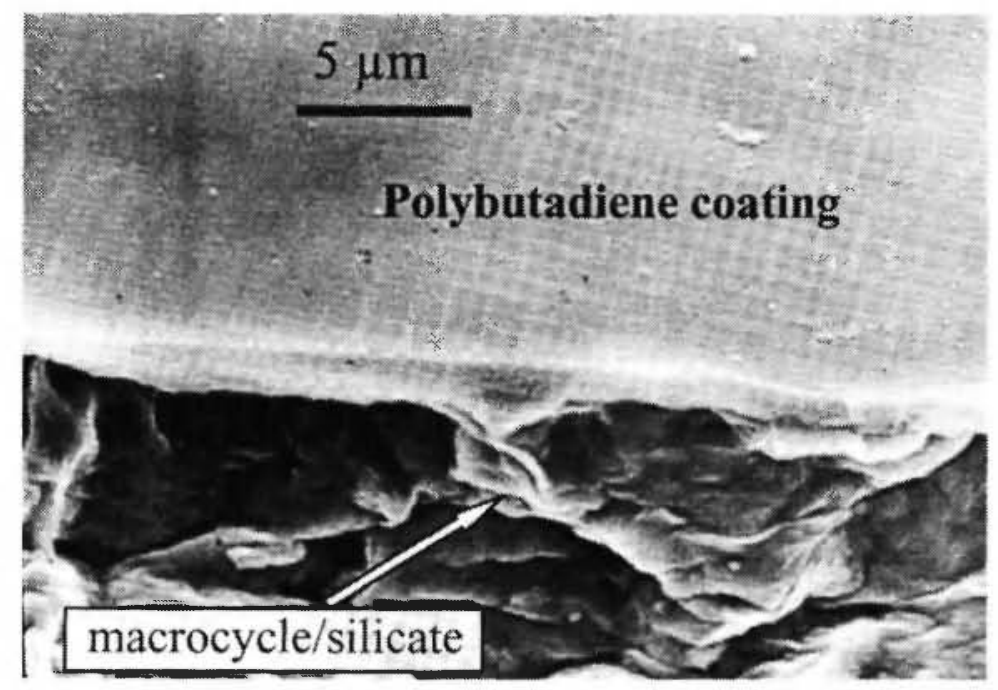

Fig. 5: SEM image showing the cross-section of a composite membrane based on 18C6/Na-montmorillonite intercalation compound sandwiched by polybutadiene thin coatings.

the $(\mathbf{a}, \mathbf{b})$ plane of the silicate. However, the lack of a perfect connectivity is the origin of channels between particles, through which the electrolyte could pass freely. Nevertheless, the excellent uniformity of the polybutadiene coating on each of the membrane faces has been clearly evidenced from the SEM study $/ 24 /$.

The ionic transport in these composite membranes, when they are in contact with aqueous salt solutions, was investigated by applying the electrochemical impedance spectroscopy technique, that informs about the facility of ions to traverse the membrane (ionic electrical conductivity) as well as other electrochemical parameters $/ 24,25 /$. The most significant feature is perhaps the extremely different behaviour of membranes containing nonintercalated clays, compared to membranes assembled from crown-ether/clay complexes. Thus, membranes based on Na-montmorillonite alone behave like a pure electrical resistance, allowing the free passage of the electrolyte, whereby the system loses the typical characteristics of a membrane. Membranes containing intercalated crown-ethers give ionic resistance values that could be correlated with the presence of the complexing agents inside the layers of the host silicate. Besides, in addition to the ionic resistance, other 
electrochemical parameters appear, like the geometric capacitance associated with the dielectric behaviour of the membrane. From the impedance measurements, it has been pointed out that the ionic resistance of the whole membrane depends not only on the intrinsic nature of its bulk material, but also on the nature of the selected electrolyte, as well as on the thickness of the polybutadiene coating.

A set of tests has been reported on this new class of membranes containing crown-ether/silicate systems, using the impedance technique 124 , 25 / with the view of determining the ionic selectivity of the membranes which is directly related to the ionic resistance $\left(R_{1}\right)$. The corresponding results indicate that, in general, they show low selectivity towards metal-ions in salt solutions. For instance, in the case of alkaline ions the following sequence has been deduced:

$$
\left(\mathrm{R}_{\mathrm{i}}\right)_{\mathrm{Li}}^{+}>\left(\mathrm{R}_{1}\right)_{\mathrm{Na}^{+}}^{+} \sim\left(\mathrm{R}_{\mathrm{i}}\right)_{\mathrm{K}}^{+} \sim\left(\mathrm{R}_{\mathrm{i}}\right)_{\mathrm{Cs}^{+}}^{+},
$$

showing that the ion size of the hydrated cations affects their passage through the membrane $/ 24 /$. Therefore, the observed ionic selectivity may be at least partially explained by a sieve effect, due to the migration of the electrolyte through the channels of the membrane, following a diffusion mechanism (passive transport). Nevertheless, considering the large amount of water retained by the membrane as deduced from the $C_{g}$ capacitance $124,26 /$, the silicate intercalation compound could be in a colloidal state, which can simultaneously contribute to a facilitated transport. In this way, the high resistance found (Fig. 6) for tetrabutylammonium (voluminous cation) and $\mathrm{Ca}^{2+}$ (high hydration energy), in their passage through a composite membrane based on $18 \mathrm{C} 6 / \mathrm{Na}$-montmorillonite, can be explained either because this crown-ether does not form stable complexes with both type of cations or by the sieve effect $/ 24 /$. The predominance of either passive or facilitated transport mechanism in these membranes has not yet been resolved. This and other important issues on membranes incorporating macrocycles still require deeper studies.

\subsubsection{Solid electrolytes}

The inorganic-organic materials resulting from the intercalation of crownethers into montmorillonite could be regarded as solid electrolytes, because they present ionic conductivity associated with the presence of interlayer cations. The starting layer silicates exhibit conductivity which is only 


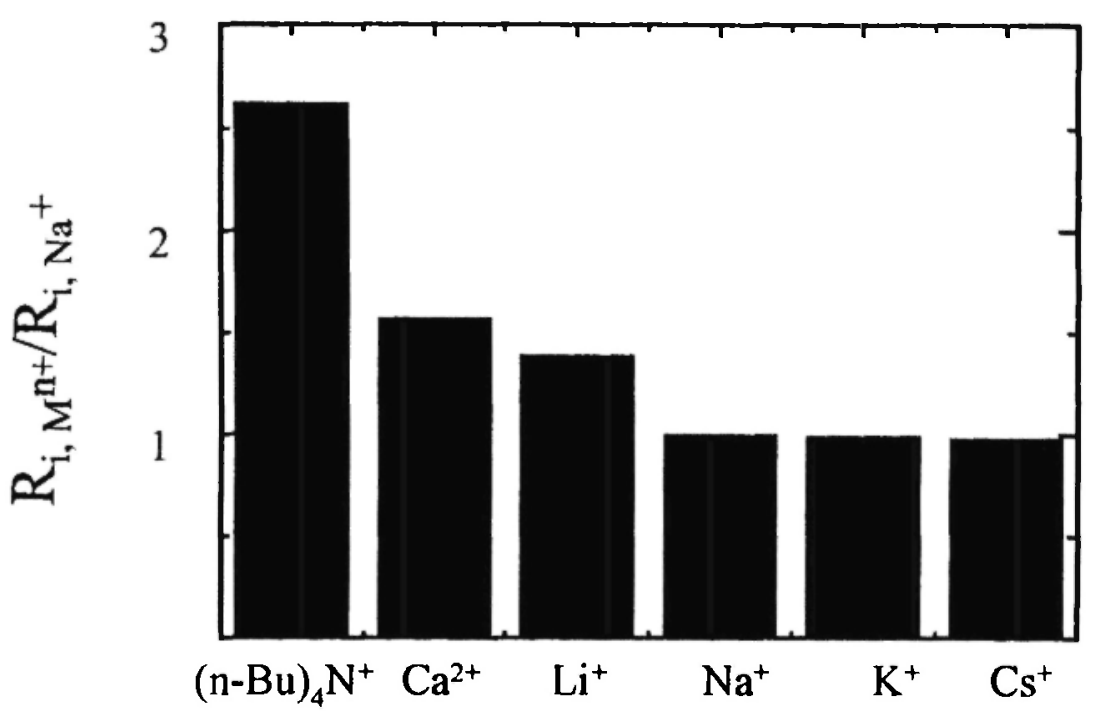

Fig. 6: Ion-selectivity over $\mathrm{Na}^{+}$cations $(=1)$ deduced from the relative ionic resistance of a composite membrane of $18 \mathrm{C} 6 / \mathrm{Na}$-montmorillonite coated by polybutadiene $/ 24$ / exposed to different electrolytes $\left(10^{-2}\right.$ M solutions).

appreciable at high temperature, i.e. above $350^{\circ} \mathrm{C}$. The thermal elimination of water provokes the collapsing of the layers that entrap the cations preventing their mobility. Intercalation of crown-ethers into these phyllosilicates prevents the collapsing of the layers, providing an adequate environment for the mobility of the cations. The ionic conductivity of crownether/phyllosilicate nanocomposites is, by several orders of magnitude, higher than that of the pristine host silicate. In these nanocomposite materials the conductivity increases with temperature up to a maximum value, which depends on the nature of the intercalated crown-ether $/ 27 \%$. It has been found $127,28 /$ that the conductivity of these intercalation compounds depends on the interaction strengths between the interlayer $\mathrm{M}^{+}$cations and the oxyethylene macrocyclic ligand, which form complexes that restrain the $\mathrm{M}^{+}$ion-mobility. So, lower conductivities were found for the best fitting of crown-ethers and interlayer cations (e.g. 15C5/Na-montmorillonite) (Table 2). On the contrary, weaker cation-interactions of macrocycles with the largest cavities, as for instance $\mathrm{DB} 24 \mathrm{C} 8$, can be invoked to explain the higher conductivity values found in the corresponding intercalation complexes in $\mathrm{Na}$-montmorillonite (Table 2). 


\section{Table 2}

Specific electrical conductivity $(\mathrm{S} / \mathrm{cm})$ range of some examples of macrocycles $/ 2 \mathrm{D}$ inorganic solid nanocomposites. In parentheses: temperature of the conductivity measurement.

\begin{tabular}{|l|c|c|c|}
\hline \multicolumn{1}{|c|}{ Layered solid } & Macrocycle & $\begin{array}{c}\text { Conductivity } \\
(\mathbf{S} / \mathbf{c m})\end{array}$ & References \\
\hline 2:1 charged & $15 \mathrm{C} 5$ & $7 \cdot 10^{-7}(600 \mathrm{~K})$ & \\
phyllosilicates & $18 \mathrm{C} 6$ & $2 \cdot 10^{-7}(550 \mathrm{~K})$ & 27,28 \\
(montmorillonite) & $\mathrm{DB} 24 \mathrm{C} 8$ & $10^{-5}(550 \mathrm{~K})$ & \\
\hline transition-metal & $12 \mathrm{C} 4$ & $3 \cdot 10^{-5}(350 \mathrm{~K})$ & 35 \\
oxides & $12 \mathrm{C} 4$ & $1.4 \cdot 10^{-4}(450 \mathrm{~K})$ & 35 \\
$\left(\mathrm{~V}_{2} \mathrm{O}_{5}\right.$ xerogel) & $15 \mathrm{C} 5$ & $2.2 \cdot 10^{-4}(450 \mathrm{~K})$ & 28 \\
\hline transition-metal & & & 86 \\
sulphides & $\mathrm{AZA} 18 \mathrm{C} 6$ & $<10^{-8}(400 \mathrm{~K})$ & \\
$\left(\right.$ TiS $\left.{ }_{2}\right)$ & & & 40 \\
\hline transition-metal & $12 \mathrm{C} 4$ & & \\
sulphides & $15 \mathrm{C} 5$ & $10^{-1}-10^{-2}(300 \mathrm{~K})$ & \\
(lithiated- & $18 \mathrm{C} 6$ & & \\
delaminated $\left.\mathrm{MoS}_{2}\right)$ & & & \\
\hline
\end{tabular}

Related with these materials, a polymer of similar composition to the crown-ethers as poly(ethylene oxide), PEO, is well known to act as solvent of metal-salts giving polymer electrolytes, which are materials with good ionconductivity at moderate temperatures $\left(<100^{\circ} \mathrm{C}\right) / 29 /$. It was first reported by Ruiz-Hitzky and Aranda $/ 30 /$, that PEO can be intercalated into 2:1 charged phyllosilicates interacting with the interlayer cations, as shown by the IR, ${ }^{13} \mathrm{C}$ and ${ }^{23} \mathrm{Na} \mathrm{NMR}$ spectroscopic data $/ 31 /$. The increase of the interlayer distance $\left(\Delta \mathrm{d}_{\mathrm{L}}\right)$ is close to $8 \AA$, allowing postulation of a helical structure of the intercalated polymer (Fig. 7) that could facilitate the ion-mobility in the inorganic-organic system and, therefore, the transport of the electrical current.

Interestingly, in the solid electrolytes based on oxyethylene (macrocyclic and polymeric) intercalated compounds, the contribution of the anions (negatively charged silicate layers) to the conductivity can be considered null, as opposed to "conventional" solid electrolytes based on oxyethylenes. So, 


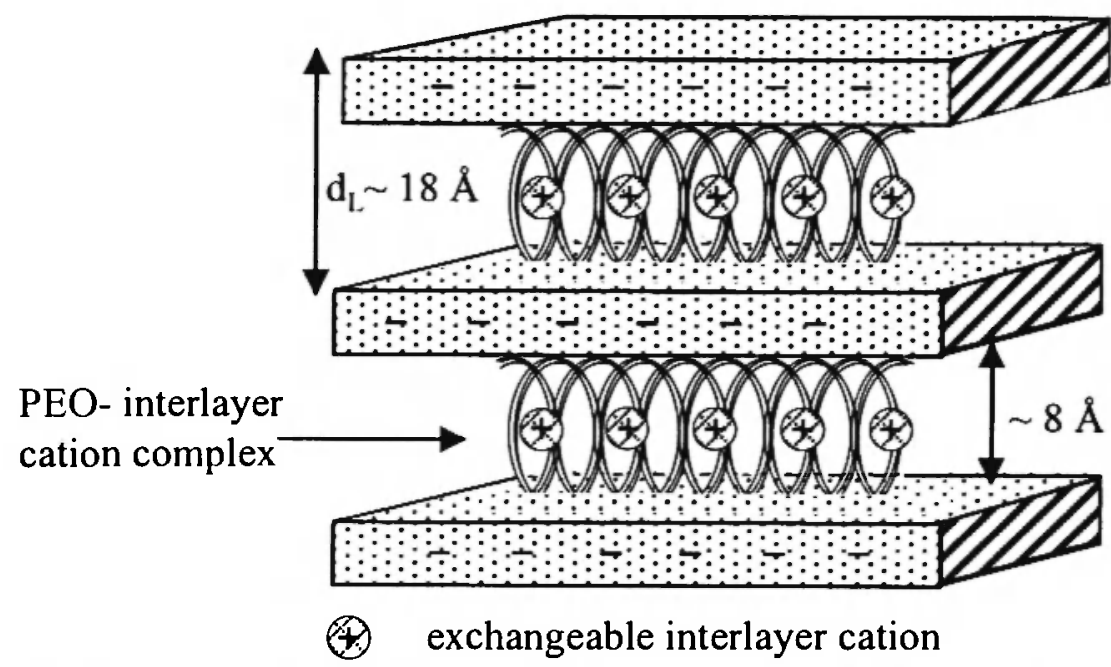

Fig. 7: Structural model representing the arrangement of PEO intercalated into a homoionic $2: 1$ charged phyllosilicate showing a helical conformation according to ref. 30 .

the transport cationic number $\left(t_{+}\right)$in the intercalation materials, determined by solid state chrono-amperometry, is very close to unity, confirming the immobility of the anions $/ 32 /$.

These results indicate the possibility to control the ionic conductivity of an inorganic host lattice, as in the case of $2: 1$ charged phyllosilicate, by choosing the appropriate guest species, and they could be useful in the design of new inorganic-organic electrolyte materials. The layers composing these silicates must be regarded like electric ceramic isolators. It appears an interesting challenge to use inorganic host lattices with different electrical behaviour (conductors, semiconductors, etc.).

\section{MACROCYCLE INTERCALATIONS IN OTHER 2D SOLIDS}

After intercalation of macrocyclic polyethers and PEO into layer silicates, other inorganic solids have been used to prepare new nanocomposites derived from such oxyethylene compounds as have been recently reviewed /lc,33/. Thus, hydrated vanadium pentoxide $\left(\mathrm{V}_{2} \mathrm{O}_{5}\right.$ xerogel: $\left.\mathrm{V}_{2} \mathrm{O}_{5} n \mathrm{H}_{2} \mathrm{O}\right) / 28,34 / 35 /$, transition-metal dichalcogenides $\left(\mathrm{MS}_{2}, \mathrm{M}=\mathrm{Mo}, \mathrm{Ti}\right) / 36,37 /$ and phosphorus trichalcogenides $\left(\mathrm{MPS}_{3}, \mathrm{M}=\mathrm{Cd}, \mathrm{Mn}\right) / 38 /$ were used as host lattices. 
Vanadium pentoxide xerogels are versatile layered solids able to intercalate a wide variety of ionic and molecular species /39/. Different effects, such as ion exchange, hydrogen bonding, charge transfer, and redox reactions are involved in those intercalations. Thus, polyethers can be easily incorporated into $\mathrm{V}_{2} \mathrm{O}_{5}$ xerogel, either from aqueous dispersions followed by slow drying, as described by Liu and co-workers $/ 34 /$, or by treatment of selfsupporting films with water/methanol mixtures that control the PEO penetration into the interlayer region /35/. The electrical properties of $\mathrm{V}_{2} \mathrm{O}_{3}$ intercalation materials have shown that these compounds keep their electronic conductivity, but the ionic conductivity, associated with remaining proton/water molecules or the presence of metal ions like $\mathrm{Li}^{+}$introduced by ion-exchange, can be reduced and controlled depending on the nature of the intercalated macrocyclic compound $/ 28,35 /$. Intercalation of crown-ethers produces a partial replacement of interlayer water molecules and a complexation of some protonated water molecules $\left(\mathrm{H}_{3} \mathrm{O}^{+}\right)$, as inferred from IR spectra of the $12 \mathrm{C} 4$ and $15 \mathrm{C} 5 / \mathrm{V}_{2} \mathrm{O}_{5}$ xerogel intercalation compounds $/ 35 /$. The interest of these $\mathrm{V}_{2} \mathrm{O}_{5}$ intercalation compounds is the possibility to prepare composite materials that exhibit both electronic and well-controlled ionic conductivities. They can be prepared as self-supporting films which, together with the strong water content reduction of starting $\mathrm{V}_{2} \mathrm{O}_{3}$ xerogel, afford characteristics of great interest in solid-state battery and electrochromic display applications. Zig-zag chain conformations in monoor bi-layer arrangements are proposed for PEO- $\mathrm{V}_{2} \mathrm{O}_{5}$ nanocomposites, in place of helical conformations ascribed to PEO-silicates.

Transition-metal dichalcogenides such as $\mathrm{MoS}_{2}$ and $\mathrm{TiS}_{2}$, which are semiconductors, act also as host lattices for polyether (crown-ether and PEO) intercalations $/ 36,37 /$. The method requires previous lithium insertion into the band gap region of the chalcogenides by $n$-butyllithium reaction, followed by subsequent treatment with polyethers or polyethers- $\mathrm{Li}^{+}$salt complexes in aqueous solution as represented in Fig. 8.

A significant increase of the electrical conductivity was reported $/ 36,40$ / after intercalation of the host lattices following the above procedure (Table 2). Such increase affecting the electronic conductivity could be related to a reduction of transition-metals, e.g. Mo (IV), belonging to the host lattice, which is accompanied by important structural modifications $(2 H \rightarrow 1 T) / 41 /$. In this way it should be assumed that the $n$-BuLi treatment is at the origin of the reported changes in the electrical properties of the resulting materials. 


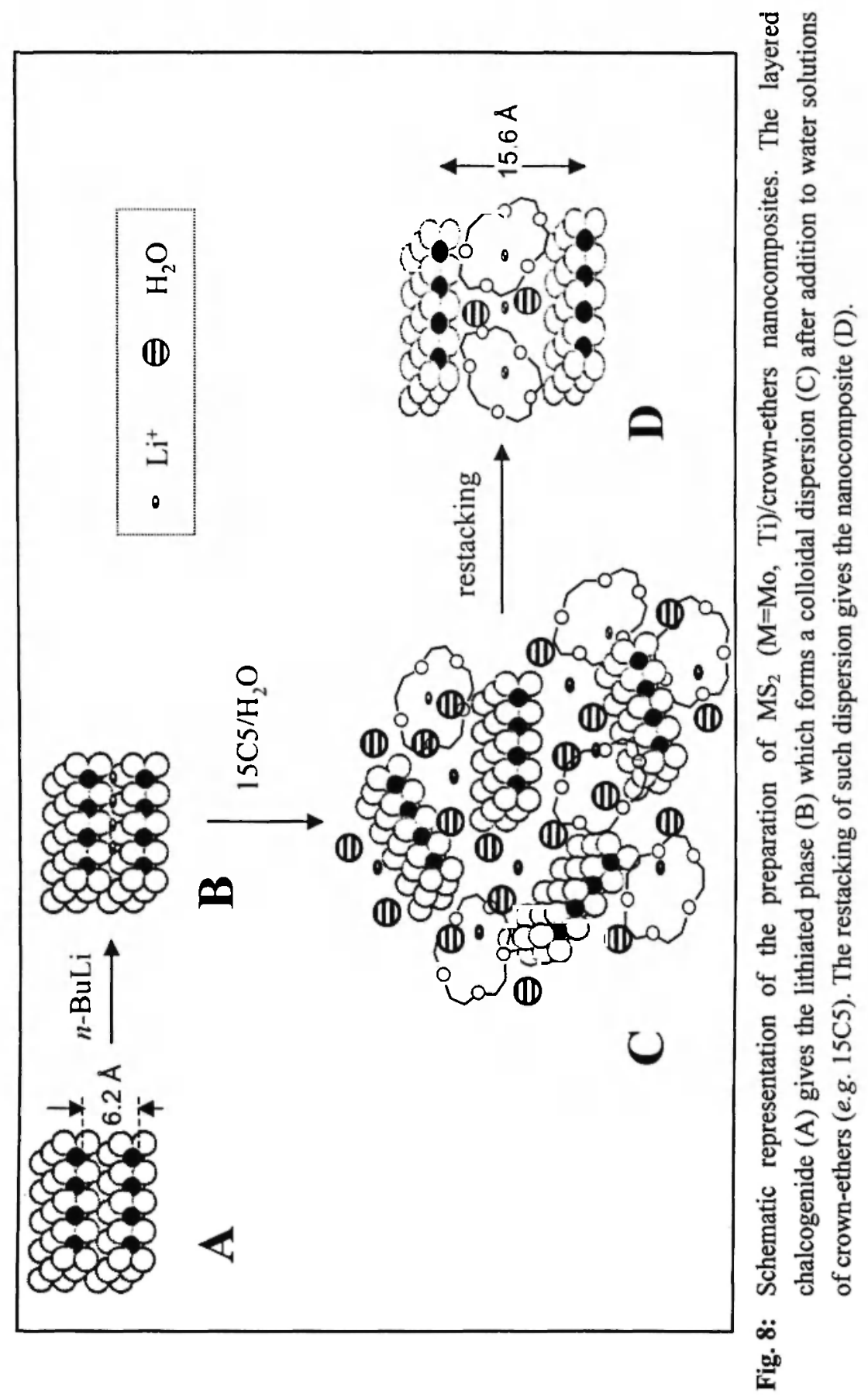


Transition-metal phosphorus trichalcogenides, $\mathrm{MPS}_{3}(\mathrm{M}=\mathrm{Mn}, \mathrm{Cd})$, containing alkaline metal-ions in the interlayer space that have been previously introduced, can also intercalate different crown-ethers giving stable nanocomposites $/ 42 /$. It seems that the low electrical conductivity of these materials causes difficulty in their application to building electrochemical devices based on such inorganic-organic solids.

\section{ENTRAPPING OF MACROCYCLIC LIGANDS IN MATRICES PREPARED BY SOL-GEL}

The entrapping of macrocyclic compounds in sol-gel matrices provides an useful route to prepare inorganic-organic hybrid materials for diverse applications as facilitated transport membranes, and ion-selective electrodes /43/, as well as catalysts $/ 44 /$, optical and opto-electronic devices $/ 45 /$, etc. Such a procedure is a way to obtain composite membranes, incorporating neutral ligands which have been selected to obtain active phases of composite membranes for ion-transport between two media. The fact that macrocyclic compounds present variable affinity towards metal-ions has been used to prepare liquid membranes that are useful for ionic separations working with a facilitated transport mechanism $/ 46 /$. As liquid membranes are unsuitable for many industrial applications, the inclusion of macrocyclic ligands into polymers, like PVC, has been employed to prepare membranes acting as selective electrodes $122,47,48 /$. It appears that, in these conditions, the physically entrapped macrocyclic compounds can still work following a facilitated transport mechanism similar to that observed for liquid membranes 149/. More recently, the so-called pseudo crown-ethers, produced from poly(ethylene glycol) diacrylate complexes, have been used to prepare facilitated ion-transport composite membranes showing high selectivity for alkaline cations over transition and lanthanide metal ions $150 /$.

We have reported above (\$2.3.2) on the behaviour of membranes containing crown-ethers intercalated into $2: 1$ phyllosilicates, showing contradictory effects to explain the transport mechanism of metal-ions. In this case, the participation of the macrocycles as carriers of such cations remains unclear. The procedure involving sol-gel processes to physically entrap macrocyclic compounds is an interesting way to prepare new composite membranes potentially useful for facilitated ion-transport purposes. Synthesis 
of the active phase of these composite membranes has been achieved by controlled hydrolysis and polycondensation of different organosilanes (precursors) like tetramethoxyortosilicate (TMOS), tetraethoxyortosilicate (TEOS), ethyltriethoxysilane (ETEOS), $\gamma$-methacryloxypropyltrimethoxysilane (MAPTMS), etc., in the presence of a macrocycle 151-53/. For instance, typical hydrolysis and polycondensation reactions of an alkylethoxysilane, like ETEOS $/ 54 /$, proceeds as represented in equation 3 :

$\left.\mathrm{n}\left(\mathrm{C}_{2} \mathrm{H}_{5} \mathrm{O}\right)_{3} \mathrm{Si}-\mathrm{CH}_{2}-\mathrm{CH}_{3} \longrightarrow \stackrel{\left[\mathrm{H}_{2} \mathrm{O}\right]}{\longrightarrow} \stackrel{\stackrel{\mathrm{O}}{\mathrm{O}}}{\mathrm{O}}-\mathrm{CH}_{2}-\mathrm{CH}_{3}\right)_{\mathrm{n}}+3 \mathrm{n} \mathrm{C}_{2} \mathrm{H}_{5} \mathrm{OH}$

ETEOS

ethylpolysiloxane

The crown-ethers are incorporated into the sol-phase giving, after drying and aging, xerogels that evolve to colourless and transparent glasses. Cryptands, such as $\mathrm{C}(222)$, induce a base-catalysed sol-gel transition that drastically changes the nature of the resulting polysiloxane network /52/. Characterization by chemical and thermal analysis, FTIR and NMR spectroscopies and SEM, evidences the homogeneous distribution of the entrapped macrocycles in the polyorganosiloxane network. Some of the resulting materials present suitable rheological properties to be conformed as films by coating. Such films will constitute the active phase of membranes and electrodes. The use of precursors as TEOS or TMOS, incorporating crown-ethers like $12 \mathrm{C} 4,15 \mathrm{C} 5$ and $18 \mathrm{C} 6$, generates organosiloxane matrices with low flexibility, causing high fragility that prevents their use for membrane preparations. Organosilanes containing $=\mathrm{Si}-\mathrm{R}$ alkyl- or alkenylchains, such as ETEOS and MAPTMS, give organopolysiloxane matrices with good physical properties with a view to their being processed as continuous films. These properties could be optimised using mixtures of precursors as MAPTMS and TMOS $153 /$. In addition, to improve mechanical behaviour of membranes, the use of supports like borosilicate or PAN was shown to be a useful method.

Electrochemical impedance spectroscopy studies of these composite membranes and electrode-membranes have been carried out to evaluate their ionic transport properties when they are placed in contact with aqueous salt solutions. The representation of the impedance data for the membranes in the complex plane shows typical Nyquist diagrams, with a well-defined single semicircle associated with the ionic resistance values of the membranes, 
which vary according to the nature and concentration of the involved macrocyclic compound. Thus, in the case of membranes containing a 1:15 macrocycle/ETEOS ratio in contact with $10^{-2} \mathrm{M} \mathrm{NaCl}$ solutions, the sequence in the values of $R_{i}$ falls in accordance with the nature of the crown-ether in the membrane following the order:

$$
\text { blank }>>15 \mathrm{C} 5>18 \mathrm{C} 6>12 \mathrm{C} 4
$$

For membranes with higher content in macrocycles (1:5) such sequence changes to:

$$
\text { blank }>>12 \mathrm{C} 4>18 \mathrm{C} 6>15 \mathrm{C} 5
$$

In both cases, the presence of these macrocycles produces a significant decrease in the ionic resistance compared to membranes without macrocyclic compounds. It has been reported that the ionic resistance of these systems is also strongly related to the nature and concentration of the electrolyte $/ 51$, $52 /$. This behaviour is interpreted on the basis that cations exhibiting greater hydration energies show the higher ionic resistance.

The selectivity of the membranes towards different cations, as well as the reversibility of the electrochemical response when nature and concentration of ions are changed, suggests the interest of these materials to development of electrochemical sensors. Therefore, potentiometric sensors based on organopolysiloxane matrices, using a mixture of MAPTMS and TMOS as precursors to entrap different macrocyclic compounds $(12 \mathrm{C} 4,15 \mathrm{C} 5,18 \mathrm{C} 6$, MAO and nonactin), have been developed $/ 53,55,56 /$. The resulting xerogels are deposited onto metal substrates to prepare new ion-selective electrodes. The active phase of the composite membranes of these electrodes was designed following different alternatives in function of the cation to detect. Thus, for example, to obtain a selective response to potassium ions, $18 \mathrm{C} 6$ ether and $\mathrm{KB}\left(\mathrm{C}_{6} \mathrm{H}_{5}\right)_{4}$ was incorporated into the sol-phase during the preparation process of the membrane, whereas for sodium ions detection, $15 \mathrm{C} 5$ and $\mathrm{NaB}\left(\mathrm{C}_{6} \mathrm{H}_{5}\right)_{4}$ were added to that sol-phase. Preliminary results show that these electrodes are very sensitive to alkaline cations, lead, silver and ammonium ions, giving linear potentiometric responses with near-Nernstian slopes in wide cation concentration ranges $/ 57 /$ (Fig. 9). These new systems constitute an alternative to "conventional" (i.e., with internal solutions or PVC) electrodes, presenting additional advantages over the latter ones, such as better sensibility, reproducibility, detection limit and adhesion behaviour. 


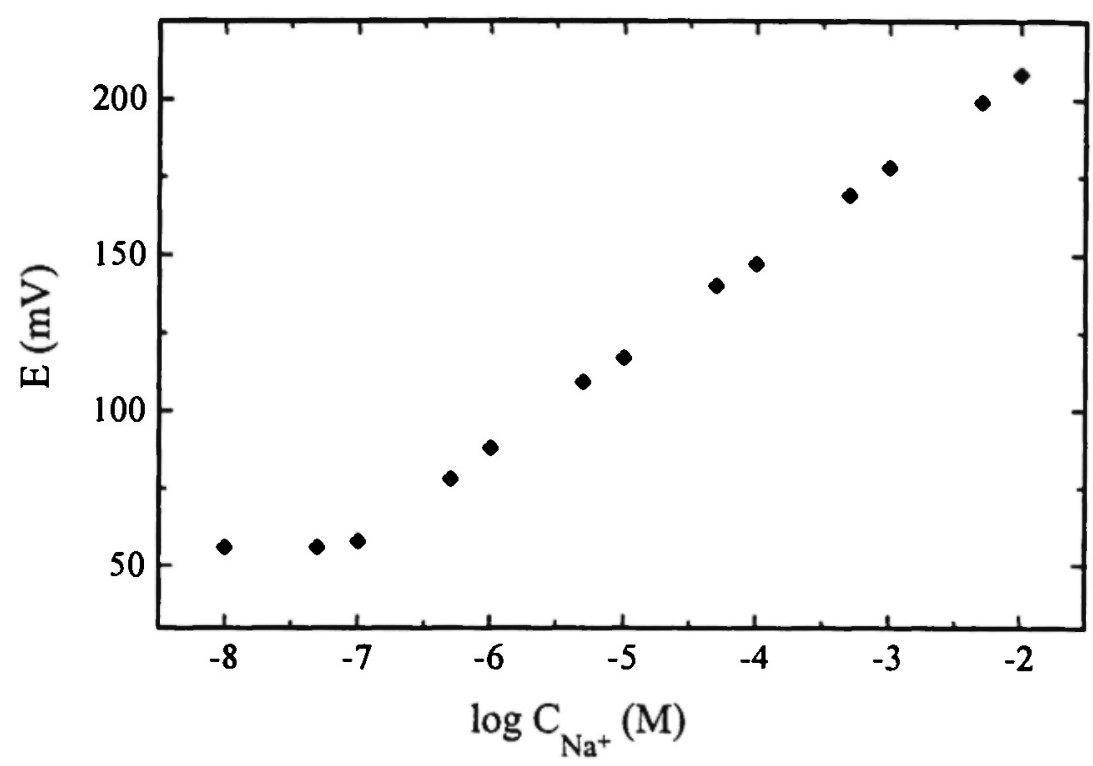

Fig. 9: Potentiometric response of an ion-selective electrode assembled with an polyorganosiloxane membrane containing $18 \mathrm{C} 6$ and $\mathrm{NaB}\left(\mathrm{C}_{6} \mathrm{H}_{5}\right)_{4}$ (55-57). Electrolyte: $\mathrm{NaCl}$ solutions.

Facilitated transport membranes, with benzo-15C5 crown-ether grafted to a heteropolysiloxane matrix as the sensitive phase, have been reported by Lacan et al: $/ 58 /$. Such membranes were tested for different processes as gas separation, nanofiltration, and also for $\mathrm{pH}$ sensors. Kimura et al. /59/ have also described neutral-carrier-type ion-sensing membranes based on sol-gel. They have used neutral carriers as valinomycin and a bis-12C4-derivative for ion-sensitive field-effect transistors (ISFETs) applications. A tetraphenylborate anion was also bound chemically to these neutral carriers 159/. In the same way, Reinhoudten et al. (60) have developed durable $\mathrm{K}^{+}$selective chemically modified field effect transistors (CHEMFETs) with funtionalized polysiloxane membranes of different polarity, i.e., with different amounts of cyanopropylsiloxane groups, incorporating either a free or a covalently bound hemispherand as valinomycine ionophore bonded to tetraphenylborate anions. 


\section{GRAFTING OF MACROCYCLES ON SILICA SURFACES}

Silica and certain microcrystalline silicates can be functionalised in order to introduce a large variety of organic groups able to confer specific properties and reactivity to the inorganic substrate. The resulting nanocomposite materials are formed by grafting of organic or organometallic reagents with surface silanol groups $(=\mathrm{Si}-\mathrm{OH})$, present in amorphous and layered silica and also in some silicates as sepiolite $/ 61 /$. The organic groups covering the silica surface are covalently linked, generally through siloxane ( $\equiv \mathrm{Si}-\mathrm{O}-\mathrm{Si} \equiv$ ) bridges, when the reagents are organoalkoxysilanes or organohalogenosilanes. In some cases, epoxides and isocyanates can be also employed in grafting reactions $162 /$.

Immobilisation of macrocyclic polyethers has been carried out by anchorage of a wide variety of benzo-crowns, benzo-azacrowns and benzocryptands on polystyrene resins and other polymers (polyamides, polysiloxanes, etc.), as reviewed by Blasius et al. $/ 63 /$.

Grafting of macrocycles on silicagel (Fig. 10) could be achieved following two general approaches: i) activation of the silica surface (e.g. by anchorage of a trialkoxysilane) and further reaction with functionalised receptive macrocycles, and ii) synthesis of reactive silanes containing macrocycles followed by its direct reaction with the surface silanol groups. Examples of these reactions are the coupling between a functionalised silica containing benzylchloride groups with a benzo-crown $/ 64 /$, and the reaction between a crown functionalised by linkage to an ethoxysilane, that is subsequently grafted on the silica surface $165 /$. In certain cases it is useful to modify the silica reactivity, and also to design functionalised macrocycles to improve the coupling between the inorganic and the organic moieties. This is for instance the case of silica immobilising benzo-crowns reported by Nakajima et al. 166/ and Iwachido et al. /67/. The so-called "spacer" groups of different length have been used to vary the distance between the macrocycle and the silica surface, searching for a better ion-binding interaction between the macrocycle and cations in solution, facilitating the use of these nanocomposites in different applications. In fact, by varying this and other parameters (nature of the silica, i.e. its porosity, nature of the organosilanes, etc.) it is theoretically possible to design "tailor-made" macrocycle-silica derivatives for pre-determined applications. However, as shown by Lindoy, success in this area has till now been achieved in only a few instances $\% 68 \%$. 


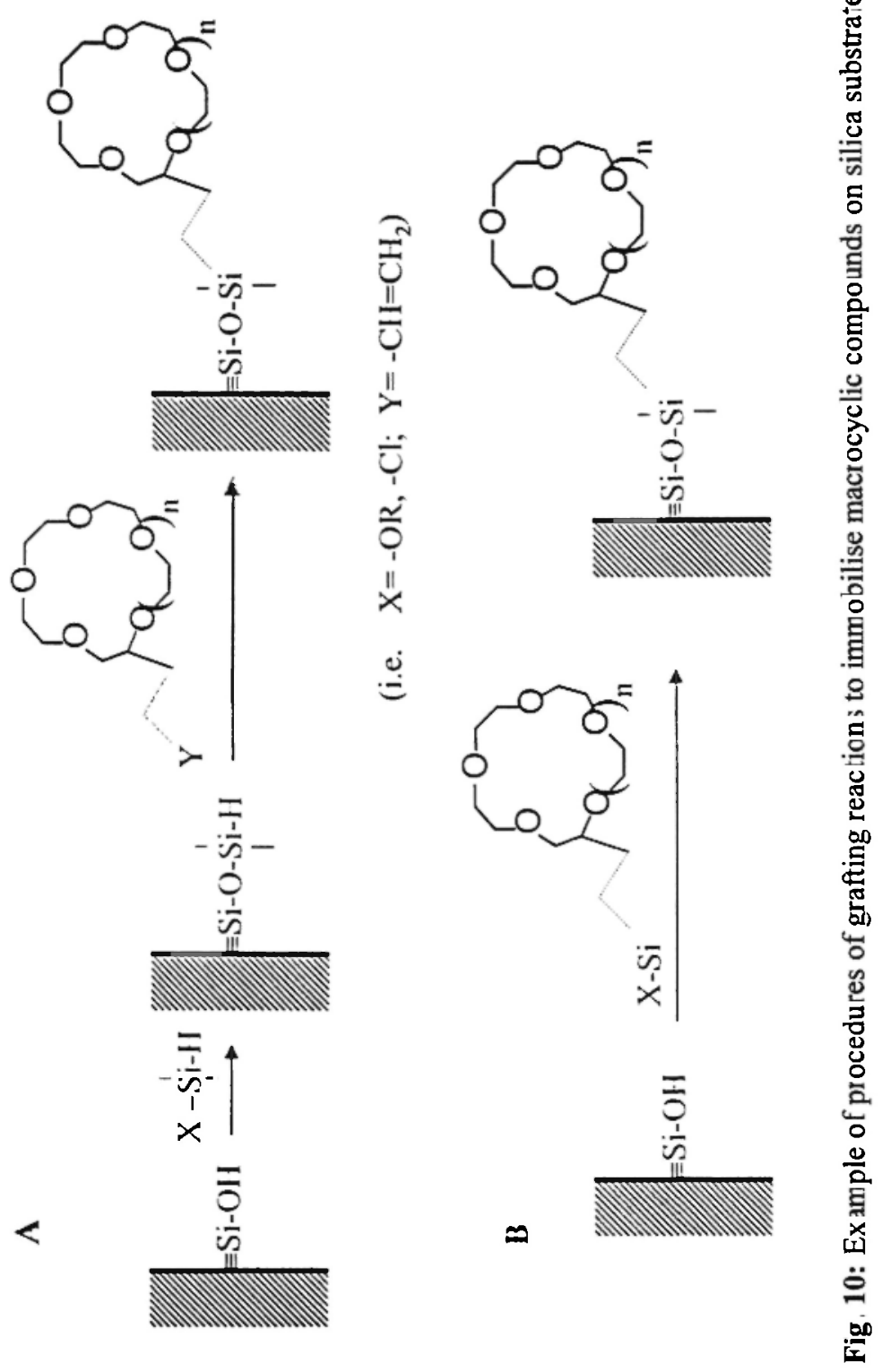


The first applications of nanocomposites based on silica-macrocycles were focused towards analytical chemistry for different chromatography purposes, as separation of cations (e.g., alkaline and alkaline earth, heavy and noble metals), separation of anions (e.g., halides, pseudohalides, isopolyacids, heteropolyacids), separation of non-electrolytic organic compounds and determination of water in inorganic and organic compounds $163,69 /$. Thus, applications in separations of cations has been investigated using inorganic-organic systems containing different macrocyclic polyethers $165,70 /$. For instance, the use of benzo-crowns, as poly(B15C5), immobilised on silica is useful for alkaline metal chlorides separations using water as mobile phase. Separation of anions as isocyanides, sulphates and bicarbonates could be also accomplished, in this case using silica coated with cross-linked DB18C6 as stationary phase $166,71 /$. The nature of the whole immobilised system and the type of involved macrocycle strongly influences the effectiveness of separations. For instance, benzo-crowns linked by different ways to silica exhibit variable separation ability towards alkaline ions. Thus, a B15C5-silica column does not show discrimination between $\mathrm{Na}^{+}$over $\mathrm{Cs}^{+}$and a B21C7-silica column does not separate $\mathrm{Li}^{+}$from $\mathrm{Na}^{+}$, neither $\mathrm{Rb}^{+}$from $\mathrm{Cs}^{+}$. Nevertheless, B18C6-silica columns show excellent discrimination of cations with retention time increasing in the sequence:

$$
\mathrm{Li}^{+}<\mathrm{Na}^{+}<\mathrm{Rb}^{+}<\mathrm{Cs}^{+}<\mathrm{K}^{+}
$$

which could be directly correlated with the stability sequence of the corresponding crown-ether/cation complexes $167 \%$ More recently, Hankins et al. /71/ have immobilized crown-ethers with vinyl groups on silica gels, for applications in columns for concentration of alkaline metal cations from dilute aqueous solutions The possibility to resolve racemic mixtures using resins incorporating chiral crown-ethers was demonstrated by Cram and coworkers $/ 72 /$. Interestingly, chiral crowns grafted on silica /73/ also show these properties, with the advantage inherent in working with heterogeneous systems (easy handling, recovering, etc.). An example of that is the use of ( $R, R$ )-bis(dinaphto-22-crown-6) derivatives immobilised on silica, giving excellent separation ratios of racemics as phenylglycine perchlorate, methyl phenylalaninate hydrocloride, etc.

Membranes based on crown-ethers grafted on silica have been prepared with a view to their application as facilitated transport membranes and ionselective electrodes $158,74,75 /$. In this way, some of these systems could 
combine the action of a solid membrane and a liquid membrane, i.e. electrostatic interactions with selective complexation by a specific carrier. This approach is quite similar to that discussed above for crown-ether intercalation membranes and ion-selective electrodes based on macrocycles entrapped into sol-gel matrices $/ 24,33 a, 52,53 /$.

Other applications of silica-macrocycles nanocomposites are related to the reactivity of the crown-ethers for anionic activations and PTC processes. For instance, the alkylation of potassium acetate $\left(110^{\circ} \mathrm{C}\right.$, toluene/water) (Eq. 4):

$$
n-\mathrm{C}_{8} \mathrm{H}_{17}-\mathrm{Br}+\mathrm{CH}_{3} \mathrm{COOK} \longrightarrow \mathrm{KBr}+n-\mathrm{C}_{8} \mathrm{H}_{17} \mathrm{COOCH}_{3}
$$

using immobilised polymeric DB18C6/69/, gives the corresponding ester with comparable yield to that obtained using other heterogeneous systems for the supported reactions based on silica, alumina or layered double hydroxides (LDH) $/ 76,77 /$.

As a final comment on this topic, it should be noted that a large number of other immobilised polyether systems, related to the above reported but containing a variety of crowns and attachment linkages, have now been synthesised, affording a large set of properties useful for different potential applications. However, it should be taken into account that crucial problems could be associated with the reproducibility of the grafting processes, given the low homogeneity in the coating of silica by the macrocycles. In addition, it appears that the resulting nanocomposite materials are often unsatisfactorily characterised, in particular by the lack of application of spectroscopic techniques (IR, NMR, etc). It should be remarked that, as usual in general trifunctional organosilanes (trialkoxysilanes) as coupling agents, uncontrolled reticulation of these reagents takes place due to the presence of water molecules adsorbed on the inorganic surfaces. In this way, unsuitable self-condensations of the organosilyl species, giving insoluble 3D silicones that remain associated to the silica substrate as an inhomogeneous material, have a great tendency to be produced. Therefore, it appears necessary to devote a great effort to synthesise well defined inorganic-organic solids containing grafted macrocyclic compounds, prior to test the behaviours inherent to these class of materials. 


\section{CONCLUSIONS}

The incorporation of macrocycles as crown-ethers, aza-crowns and cryptands into inorganic matrices is the basis for design and preparation of inorganic-organic functional materials, showing pre-determined behaviours related with the nature of both moieties, the macrocycles and the host solid. This class of nanocomposites could be prepared in different ways: intercalation, entrapping and grafting on inorganic solids.

The ability of macrocycles to act as ligands of intracrystalline cations of layered solids, as 2:1 charged phyllosilicates, allows very stable intercalation compounds to be obtained. The mobility of interlayer ions is controlled by the macrocycles inserted in such phyllosilicates. Other inorganic layered solids, containing transition-metals (oxides, chalcogenides and phosphochalcogenides), can also act as host materials, giving intercalation compounds with synergetic properties between the macrocycle and the inorganic lattice. In particular, the electrical behaviour and the ion-transport properties are the more salient characteristics of these macrocycle/2D solid nanocomposites. The wide choice of the host lattices allows to dispose of insulating, semi-conducting or conducting layered solids and interlayer cations of different nature, i.e. alkaline, alkaline-earth, transition-metal ions, etc. Besides, it should be expected that new hosts, provided with suitable properties, will be used for future intercalations of macrocycles. In this way, preliminary results of new intercalation materials have recently been found using transition-metal chalcogenides and azacrowns $/ 86 /$.

The option to include macrocycles into inorganic matrices by sol-gel opens the way to obtain a large variety of homogeneous inorganic-organic materials with physically entrapped crown-ethers. The leaching tendency of the macrocycles, when the systems are exposed to salt solutions and other liquid media, can be suppressed by grafting of such macrocycles on the inorganic (or inorganic-organic) frameworks. Polysiloxanes and silica substrates are usually employed for the entrapping and grafting of the macrocycles, but further research appears to be a priority with the aim of using inorganic conducting materials generated by sol-gel, e.g. ITO.

It has been reported that macrocycles/inorganic materials could be useful for membrane, solid-electrolyte, ion-sensor-device, and chromatography applications. The use of new macrocycles and its combination with other host solids are of special importance in view of future novel purposes as, for 
instance, the preparation of electrodic inorganic-organic materials (i.e. macrocycles/2D solids as cathodes for Li-batteries), and also for potential applications as optical and opto-electronic devices, supported molecular magnets, high selective heterogeneous catalysts and molecular sieves, etc.

\section{ACKNOWLEDGEMENTS}

Financial support from the CICYT and Fundacion Ramón Areces (Spain), and BRITE-EURAM Programme (EU), is gratefully acknowledged.

\section{REFERENCES}

1. a) E. Ruiz-Hitzky, Mol. Cryst. Liq. Cryst., 161, 433 (1988); b) G.A. Ozin, Adv. Mater., 4, 612, (1992); c) E. Ruiz-Hitzky, Adv. Mater., 5, 334 (1993); d) Special Issue on Clay-Mineral-Pohymer Nanocomposites (eds.: G. Lagaly and T.J. Pinnavaia), Appl. Clay Sci., 15, Iss. 1-2 (1999); e) T.J. Pinnavaia and G.W. Beall, eds., Polymer-Clay Nanocomposites, Wiley, New York (2000); f) Special Issue on Nanostructured Materials, Chem. Mater., 8, Issue 8 (1996); g) P. Judeinstein and C. Sanchez, J. Mater. Chem., 6, 511 (1996).

2. E. Ruiz-Hitzky and B. Casal, Nature, 276, 596 (1978).

3. U. Hoffinan, K. Endell and D. Will, Z. Krist. 86106 (1933).

4. J.A Rausell-Colom and J.M. Serratosa, in Chemistry of Clays and Clay Minerals (ed.: A.C.D. Newman), p. 371, London (1987).

5. E. Ruiz-Hitzky, B. Casal in Chemical Reactions in Organic and Inorganic Constrained Systems, (Ed: R. Setton) NATO ASI series, Serie C: Mathematical and Physical Sciences, Reidel, Dordrecht, 1986 Vol. 165, p. 179.

6. B. Casal and E. Ruiz-Hitzky, Opt. Pur. Apl., 18, 49, (1985).

7. B. Casal, E. Ruiz-Hitzky, L. Van Vaeck and F.C. Adams, J. Incl. Phenom., 6, 107 (1988).

8. B. Casal, P. Aranda, J. Sanz and E. Ruiz-Hitzky, Clay Min., 29, 191 (1994).

9. B. Casal and E. Ruiz-Hitzky, Clay Min., 21, 1 (1986).

10. R.M. Izatt, J..S. Bradshaw, S.A. Nielsen, J.D. Lamb and J.J. Christensen, Chem. Rev., 85, 271 (1985). 
11. P. Aranda, B. Casal, J.J. Fripiat and E. Ruiz-Hitzky, Langmuir, 10, 1207 (1994).

12. N.S. Poonia in Progress in Macrocyclic Chemistry Vol. I, (R.M. Izatt and J.J. Christensen, Eds), John Wiley \& Sons, New York (1979).

13. M.A. Bush and M.R. Truter, J. Chem. Soc. Perkin Trans. II, 341 (1972).

14. B. Casal, E. Ruiz-Hitzky, J.M. Serratosa and J.J. Fripiat, J. Chem. Soc. Faraday Trans. I, 80, 2225 (1984).

15. J.M. Lehn, Acc. Chem. Res. 11, 49 (1978).

16. R. Tabeta, M. Aida and H. Saito, Bull. Chem. Soc. Jpn., 59, 1957, (1986).

17. B. Casal, Ph.D. Thesis, Universidad Complutense, Madrid (1985).

18. R. Green-Kelly, Clay Min. Bull, 1, 221 (1952).

19. R.C. McKenzie (ed.), Differential Thermal Analysis, Academic Press, London \& New York (1970).

20. Y. Soma, M. Soma and I. Harada, J. Phys. Chem., 88, 3034 (1984).

21. J.H. Fendler, Membrane Mimetic Chemistry, Wiley, New York, p.184 (1982).

22. R.D. Armstrong and G. Horvai, Electrochim. Acta, 35, 1 (1990).

23. H. Strathman in Synthetic Membranes: Science, Engineering and Applications, NATO-ASI series (Edts.: P.M. Bungay, H.K. Londsdale, M.N. Pinho and J.K. Bungay), Reidel Pub., Dordrecht, 1983; Vol. 181.

24. P. Aranda, J.C. Galván, B. Casal and E. Ruiz-Hitzky, Coll. \& Polym. Sci., 272, 712 (1994).

25. P. Aranda, J.C. Galván, B. Casal and E. Ruiz-Hitzky, Key Engin. Mater., 61\&62, 469 (1991).

26. P. Aranda, Ph.D. Thesis, Universidad Complutense, Madrid (1991).

27. P. Aranda, J.C. Galván, B. Casal and E. Ruiz-Hitzky, Electrochim. Acta, 37, 1573 (1992).

28. P. Aranda, B. Casal, J.C. Galván and E. Ruiz-Hitzky in Chemical Physics of Intercalation II (Ed: P. Bernier et al.) NATO ASI Series, Plenum Press, New York 1993, p.397.

29. For example, a) M.B. Armand, Adv. Mater., 2, 278, (1990); b) J.R. MacCallum and C.A. Vincent, eds., Polymer Electrolyte Reviews -1 and -2, Elsevier Applied Science, London 1987 and 1989, respectively; c) C.A. Vincent, Chem. Brit., (1989), 391.

30. E. Ruiz-Hitzky and P. Aranda, Adv. Mater., 2, 545 (1990). 
31. P. Aranda and E. Ruiz-Hitzky, a) Chem. Mater., 4, 1395 (1992); b) Acta Polymer, 45, 59 (1994); c) Applied Clay Sci., 15, 119 (1999).

32. E. Ruiz-Hitzky, P. Aranda, E. Perez-Cappe, A. Villanueva and Y. Mosqueda-Laffita, Rev. Cubana de Quím., 12, 58 (2000).

33. a) E. Ruiz-Hitzky, P. Aranda, B. Casal and J.C. Galván, Adv. Mater., 7, 180 (1995); b) E. Ruiz-Hitzky and P. Aranda, Anales Quím. Int. Ed., 93, 197 (1997); c) E. Ruiz-Hitzky and P. Aranda in Polymer-Clay Nanocomposites (eds.: T.J. Pinnavaia and G.W. Beall), Wiley, New York, Chp. 2, p. 19 (2000).

34. Y.-J. Liu, D.C. DeGroot, J.L. Schindler, C.R. Kannewurf and M.G. Kanatzidis, Chem. Mater., 3, 992 (1991).

35. E. Ruiz-Hitzky, P. Aranda and B. Casal, J. Mater. Chem., 2, 581 (1992).

36. E. Ruiz-Hitzky, R. Jiménez, B. Casal, V. Manriquez, A. Santa Ana and G. González, Adv. Mater., 5, 738 (1993).

37. R. Bissessur, M.G. Kanatzidis, J.L. Schindler and C.R. Kannewurf, $J$. Chem. Soc., Chem. Commun., (1993) 1582.

38. I. Lagadic, A. Léaustic and R. Clément, J. Chem. Soc., Chem. Commun., (1992) 1396.

39. J. Livage, Chem. Mater., 3, 578 (1991).

40. N. Lara and E. Ruiz-Hitzky, Braz. Chem. Soc., 7, 193 (1996).

41. a) F. Wypych and R. Schöllhorn, J.Chem. Soc., Chem. Commun., (1992) 1386; b) K. Chrissafis, M. Zamani, K. Kambas, J. Stoemenos, N. Economou, J. Samaras and C. Julien, Mater. Sci. Eng., B3, 145 (1989).

42. D. S. Glueck, A.R. Brough, P. Mountford and M.L.H. Green, Inorg. Chem., 32, 1893 (1993).

43. M.M. Collins, Crit. Rev. Anal. Chem., 29, 289 (1999).

44. E. Cordoncillo, G. Monros, M.A. Tena, P. Escribano and J. Carda, $J$. Non-Crystal. Solids, 171, 105 (1994).

45. a) E. Blanco, D.N. Rao, F.J. Aranda, D.V.G.L.N. Rao, S. Tripathy, J.A. Akkara, R. Litran and M. Ramirez del Solar, J. Appl. Phys., 83, 3441 (1998); b) A.M. Klonkowski, K. Kledzik, T. Ossowski and A. Jankowska-Frydel, J. Mater. Chem., 8, 1245 (1998); c) A.M. Klonkowski, S. Lis, Z. Hnatejko, K. Czarnobaj, M. Pietraszkiewicz and M. Elbanowski, J. Alloys \& Compounds, 300, 55 (2000); d) A. Kriltz, M. Muller, R. Fachet and H. Burger, Mol. Cryst. Liq. Cryst. Sci. Technol. Section A, 297, 41 (1997). 
46. R.M. Izatt, G.C. Lindh, J.F. Biernat, M. Bochenska, R.L.Bruening, J.S. Bradshaw and J.J. Christensen, J. Incl. Phenom. \& Mol. Recogn. Chem., 7, 487 (1989).

47. R.D. Armstronga and H. Ashassi-Sorkhabi, Electrochim. Acta, 32, 135 (1987).

48. R. D. Armstrong, A.K. Covington and G.P. Evans, J. Electroanal. Chem., 159, 33 (1983).

49. J. Casabó, C. Perez-Jimenez, L.L. Escriche, S. Alegret, E. MartinezFábregas and F. Teixidor, Chem. Lett., 7, 1107 (1990).

50. B.J. Elliot, W.B. Willis and C.N. Bowman, J. Membr. Sci., 168, 109 (2000).

51. J.C. Galván, P. Aranda, J.M. Amarilla, B. Casal and E. Ruiz-Hitzky, J. Mater. Chem., 3, 687 (1993).

52. P. Aranda, A. Jiménez-Morales, J.C. Galván, B. Casal and E. RuizHitzky, J. Mater. Chem., 5, 817 (1995).

53. A. Jiménez-Morales, J.C. Galván, P. Aranda and E. Ruiz-Hitzky, in Organic/Inorganic Hybrid Materials, MRS Symp. Proc., Vol. 519 (eds.: R. M Laine, C. Sanchez, C.J. Brinker and E. Giannelis), Warrendale, p. 211 (1998).

54. C. J. Brinker and G.W. Scherer, Sol-Gel Science: The Physics and Chemistry of Sol-Gel Processing, Academic Press, Inc., San Diego (1990).

55. A. Jimenez-Morales, Ph.D. Thesis, Universidad Carlos III de Madrid (1999).

56. E. Ruiz-Hitzky, J.C. Galván, A. Jimenez-Morales and P. Aranda "Electrodos para el reconocimiento electroquímico de especies iónicas o moleculares basados en membranas polisiloxánicas" Spanish Patent P. 9900956 (date: 7/05/1999).

57. A. Jimenez-Morales, P. Aranda, J.C. Galván and E. Ruiz-Hitzky (in preparation).

58. a) C. Guizard and P. Lacan, New J. Chem., 18, 1097 (1994); b) P. Lacan, C. Guizard, P. Le Gall, D. Wettling and L. Cot, J. Membr. Sci., 100, 99 (1995).

59. a) K. Kimura, T. Sunagawa and M. Yokoyama, J. Chem. Soc., Chem. Commun., (1996) 745; b) Y. Tsujimura, T. Sunagawa, A. Yokoyama and K. Kimura, Analyst, 121, 1705 (1996); c) K. Kimura, T. Sunagawa and M. Yokoyama , Anal. Chem., 69, 2379 (1997); d) K. Kimura, T. Sunagawa, S. Yajima, S. Miyake and M. Yokoyama, Anal. Chem., 70, 4309 (1998). 
60. D.N. Reinhoudt, J.F.J. Engbersen, Z. Brzózka, H.H. van den Vlekkert, G.W.N. Honig, H.A.J. Holterman and U.H. Verkerk, Anal. Chem., 66, 3618 (1994).

61. a) E. Ruiz-Hitzky and J.J. Fripiat, Clays Clay Min., 24, 25 (1976); b) E. Ruiz-Hitzky and J.J. Fripiat, Bull. Soc. Chim., 9-10, 1341 (1976); c) E. Ruiz-Hitzky and A. Van Meerbeek, Coll. Pohym. Sci., 256, 135 (1978); d) A. Van Meerbeek and E.Ruiz-Hitzky, Coll. Polym. Sci, 257, 178 (1979); e) E. Ruiz-Hitzky and J.M. Rojo, Nature, 287, 28 (1980); f) A.J. Aznar and E. Ruiz-Hitzky, Mol. Cryst. Liq. Cryst. B., 161, 459 (1988).

62. a) M.N. Fernandez-Hernandez and E.Ruiz-Hitzky, Clay Min., 14, 295 (1979); b) B. Casal and E. Ruiz-Hitzky in Proc. III European Clay Conference Oslo 1977, Vol. I., I.Th. (ed.: I.Th. Rosenqvist), Nordic Society for Clay Research, Oslo, 1977, pp. 35; c) B. Casal and E. RuizHitzky, An. Quim., 80, 315 (1984).

63. E. Blasius, K.P. Janzen, W. Klein, H. Klotz, V.B. Nguyen; T. NguyenTien, R. Pfeiffer, G. Scholten, H. Simon, H. Stockemer and A. Toussaint,. J. Chromatogr. 201, 147 (1980).

64. T.G. Waddell and D.E. Leyden, J. Org. Chem., 46, 2406 (1981).

65. J.S. Bradshaw, R.L. Bruening, K.E. Krakowiak, B.J. Tarbet, M.L. Bruening, R.M. Izatt and J.J. Christensen, J. Chem. Soc. Chem. Commun., (1988) 812.

66. M. Nakajima, K. Kimura and T. Shono, Anal. Chem., 55, 463 (1983).

67. T. Iwachido, H. Naito, F. Samukawa, K. Ishimaru and K. Toei, Bull. Chem. Soc. Jpn., 59, 1475 (1986).

68. L.F. Lindoy, The Chemistry of Macrocyclic Ligand Complexes, Cambridge Univ. Press., Cambridge (1989).

69. E. Blasius and K.P. Janzen, Israel J. Chem., 26, 25 (1985).

70. R. M. Izatt, R. L. Bruening, M.L. Bruening, B.J. Tarbet, K.E. Krakowiak, J.S. Bradshaw and J.J. Christensen, Anal. Chem., 60, 1825 (1988).

71. M.G. Hankins, T. Hayashita, S.P. Kasprzyk and R.A. Bartsch, Anal. Chem., 68, 2811 (1996).

72. E.P. Kyba, J.M. Timko, L.J. Kaplan, F. de Jong, G.W. Gokel and D.J. Cram, J. Amer. Chem. Soc., 100, 4555 (1978).

73. K. Kimura and T.Shono, J. Liq. Chromatogr., 5, 223 (1982).

74. O. Lev, Z. Wu, S. Bharathi, V. Glezer, A. Modestov, J. Gun, L. Rabinovich and S. Sampath, Chem. Mater., 9, 2354 (1997). 
75. M. Barboiu, C. Guizard, N. Hovnanian, J. Palmeri, C. Reibel, L. Cot and C. Luca, J. Membr. Sci., 172, 91 (2000).

76. a) G. Bram, T. Fillebeen-Khan and N. Geraghty, Synthetic Commun., 10, 279 (1980); b) E. Gutierrez, A. Loupy, G. Bram and E. Ruiz-Hitzky, Tetrah. Letters, 30, 945 (1989); c) G. Bram, A. Loupy, M. Majdoub, E. Gutierrez and E. Ruiz-Hitzky, Tetrahedron, 46, 5167 (1990).

77. A.L.Garcia-Ponce, V. Prevot, B. Casal and E. Ruiz-Hitzky, New J. Chem, 24, 119 (2000).

78. J. Guignard and H. Pezerat, Cloy Min., 14, 259 (1979).

79. D.R. Kosiur, Clays Clay Miner., 25, 365 (1977).

80. S.S. Cady and T.J. Pinnavaia, Clays Clay Miner., 25, 365 (1977).

81. H. Van Damme, M. Crespin, F.Obrecht, M.I. Cruz and J.J. Fripiat, J. Colloid Interface Sci., 66, 43 (1978).

82. P. Canesson, M.I. Cruz and H. Van Damme, Int. Clay. Conf. 1978 (eds: M.M. Mortland and V.C. Farmer), Elsevier Pub., Amsterdam, 1979.

83. S. Abdo, M.I. Cruz and J.J. Fripiat, Clays Clay Miner., 28,125 (1980).

84. A.R. Guerrero-Ruiz, J. Peinado-García and J.D. López-Gônzález, An. Quim., 78, 270 (1982).

85. a) R.H. Herber and R.A. Cassell, J. Chem. Phys., 75, 4669 (1981); b) R.H. Herber and R.A. Cassell, Inorg. Chem., 21, 3713 (1982).

86. A. Villanueva and E. Ruiz-Hitzky (in preparation). 